\title{
Penguatan Satuan PAUD melalui Pendekatan Pembelajaran Berbasis STEAM dalam Pendidikan Abad 21 di Taman Kanak-kanak Islam Terpadu Nurul Hidayah Sampang
}

\author{
1Jamiludin Usman, ${ }^{2}$ Luthfatun Nisa', ${ }^{3}$ Danang Prastyo, ${ }^{4}$ Nina Khayatul Virdyna \\ Insitut Agama Islam Negeri Madura \\ 1jamiludin.usman@iainmadura.ac.id, ${ }^{2}$ luthfatunnisa@iainmadura.ac.id \\ 32danangprastyo@iainmadura.ac.id, ninananang.kazganilma@gmail.com
}

\begin{abstract}
This strengthening activity aims to optimize Early Child Education (Pendidikan Anak Usia Dini/ PAUD) institutions. The use of the STEAM approach in Early Childhood Education is carried out appropriately in the learning process in Early Childhood Education. The activity was carried out by involving 24 Kindergarten teachers in Integrated Islamic Kindergarten (TKIT) Nurul Hidayah Sampang with material on the concept and implementation of STEAM-based Early Childhood Education learning. Implementing this service program can be stated that strengthening the Early Childhood Education unit with a STEAM-based learning approach in 21 st-century education is very important to do. By collaborating methods that have been mastered by many teachers and utilizing existing media in the environment, thereby maximizing the learning process.
\end{abstract}

Keywords: STEAM; Early Childhood Education; $21^{\text {st }}$ Century

\begin{abstract}
Abstrak
Tujuan kegiatan penguatan ini adalah untuk mengoptimalkan lembaga PAUD dalam pelaksanaan pendekatan STEAM di PAUD sehingga terlaksana pembelajaran dengan pendekatan STEAM secara tepat pada proses pembelajaran di PAUD. Kegiatan dilaksanakan dengan melibatkan 24 orang guru Taman Kanak-kanak yang ada di Islam Terpadu (TKIT) Nurul Hidayah Sampang dengan materi konsep dan implementasi pembelajaran Pendidikan Anak Usia Dini berbasis STEAM. Hasil dari pelaksanaan program pengabdian ini dapat dinyatakan bahwa penguatan satuan paud dengan pendekatan pembelajaran berbasis STEAM dalam pendidikan abad 21 ini sangat penting dilakukan dengan cara mengkolaborasikan metode yang telah banyak dikuasai oleh guru-guru dan memanfaatkan media yang ada dilingkungan, sehingga memaksimalkan proses pembelajaran.
\end{abstract}

Kata Kunci: STEAM; Pendidikan Anak Usia Dini; Abad 21

\section{Pendahuluan}

Pendidikan merupakan salah satu cara yang tepat untuk memperbaiki dan memajukan kehidupan bangsa. Termasuk dalam menghadapi era 
pendidikan abad 21 ini anak-anak perlu menguasai keterampilan $4 \mathrm{C}$, yaitu creativity atau kreativitas, critical thingking atau berfikir kritis, communication atau komunikasi, dan collaboration atau kolaborasi (Pacific Policy Research Center, 2010: 1). Selain itu tuntutan dalam pendidikan abad 21 ini proses pembelajaran perlu mengintegrasikan kecakapan anak dalam pengetahuan, keterampilan, sikap serta teknologi. Menghadapi tuntutan yang ada maka pendidikan perlu dipersiapkan dan diberikan secara tepat dan disesuaikan dengan tingkat capaian saat ini.

Konsep pendidikan ini juga perlu disiapkan sejak dini, sehingga PAUD tidak bisa lepas dari tuntutan pendidikan abad 21. Bahkan menjadi tonggak untuk menanamkan keterampilan yang perlu dimiliki anak sebagai bekal dimasa depan. Sehingga, proses pembelajaran perlu untuk dirancang dan disusun dengan menyesuaikan keterampilan yang perlu dicapai saat ini. Pemilihan pendekatan yang tepat perlu menjadi perhatian, dan menyesuaikan konsep utama dari kurikulum 2013 khususnya yang diterapkan pada PAUD dengan pendekatan saintifik dan tematik holistik integratif dapat dipadukan dengan pendekatan pembelajaran berbasis Science, Technology, Engineering, Art, and Mathematics atau yang bisa disingkat STEAM, yang banyak melibatkan anak dalam proses penggalian informasi secara mandiri, mengaitkan materi pembelajaran dengan kehidupan sehari-hari sehingga dapat memberikan pengalaman langsung pada anak.

Maka perlu adanya pembaruan dan mengubah cara pembelajaran yang sesuai dengan situasi dan kondisi yanga akan dihadapi, dan hal ini perlu disadari oleh guru sebagai motor penggerak pembelajaran. Guru perlu memiliki keterampilan dalam menyiapkan pembelajaran yang mampu membekali peserta didik kemampuan dan kecakapan hidup yang disesuaikan dengan lingkungan yang dihadapi anak, dan kebutuhan era saat ini secara individual, sehinga pembelajaran dapat memberikan manfaat bagi anak dan tujuan pendidikan yang telah dirancang dapat tercapai secara efektif dan efesien (Artobatama, 2018: 41). Sayangnya, tidak semua guru menyadari akan kebutuhan pembaruan proses pembelajaran baik dalam model, pendekatan, serta metode yang perlu adanya inovasi khususnya pendekatan STEAM sebagai alternatif solusi menghadapi tuntutan kecakapan abad 21, serta implementasinya dalam proses pembelajaran bagi anak usia dini. Sehingga, perlu adanya penguatan satuan PAUD melalui kegiatan pelatihan dalam menerapkan pendekatan pembelajaran berbasis STEAM dalam proses pembelajaran.

Metode STEAM erat kaitannya dengan pendidikan abad 21, yang mengkolaborasikan antara pegetahuan dan keterampilan yang disusun dalam pembelajran agar dapat berjalan beriringan. Melalui metode STEAM, guru dapat mengajak anak bermain dengan nilai edukasi dalam berbagai situasi.

Dalam metode STEAM ini terdapat beberapa dasar-dasar keterampilan yang perlu diterapkan oleh guru dalam proses pembelajaran. Diantaranya adalah mendorong anak bertanya, bekerja bersama (terlibat dalam aktivitas 
anak), menyelesaikan masalah (problem solving), mengeksplorasi sesuatu dan mengambil resiko yang sudah diperhitungkan dampaknya bagi anak, menguji solusi suatu masalah, dan menemukan cara baru dalam melakukan sesuatu.

Dengan memberikan anak kesempatan untuk mengeksplorasi lingkungan disekelilingnya, dapat mendorong anak lebih banyak bertanya. Selain itu, dapat memberikan anak kesempatan untuk berperan aktif dalam proses pembelajaran, sehingga dapat membantu anak lebih memahami dunia disekelilingnya.

Konsep utama dalam pembelajaran STEAM adalah implementasi teori dan praktik yang berjalan bersamaan. STEAM bukan hanya metode belajar, tetapi juga cara berfikir. Melalui metode ini diharapkan anak mampu memecahkan masalah dengan berbagai pengetahuan yang dimilikinya dan bekerjasama secara penuh, tidak hanya mengandalkan sisi pengetahuan yang dimilikinya saja (Jatnika, 2019).

Melalui pembelajaran STEAM, anak akan lebih terlatih untuk cepat menganalisa permasalahan dengan berbagai pendekatan, baik sains, teknologi, teknik, seni ataupun matematika. Selan itu, anak juga terlatih untuk berfikir kritis, inovatif, dan kreatif, dan dapat mengungkapkan pendapatnya baik secara lisan maupun tulisan.

Berdasarkan wawancara dan observasi awal dengan kepala Taman Kanak-Kanak Islam Terpadu Nurul Hidayah, maka dirasa perlu untuk melaksanakan penguatan satuan PAUD dengan pendekatan pembelajaran berbasis STEAM dalam pendidikan abad 21, salah satu faktor penguat adanya tantangan pendidikan khususnya lembaga PAUD untuk menyiapkan anak didiknya memasuki industri pendidikan di abad 21 atau pendidikan 4.0 ditambah lagi pendidikan dimasa pandemi covid 19.

Oleh sebab itu perlu penguatan satuan PAUD dengan pendekatan pembelajaran berbasis STEAM dalam pendidikan abad 21 untuk menjawab tantangan pendidikan di abad 21 yang meliputi $4 \mathrm{C}$ yaitu (Communication, Collaboration, Creativity, Critical Thinking).

Berdasarkan identifikasi masalah ditentukan rumusan masalah sebagai berikut, 1). Bagaimana cara anak memperoleh keterampilan pendidikan di abad $21 ; 2$ ). Apa saja yang harus dilakukan oleh lembaga PAUD agar Pendekatan STEAMini dapat berjalan secara optimal; 3). Bagaimana Implementasi dari pendekatan STEAM pada proses Pembelajaran di PAUD?

Berdasarkan identifikasi masalah ditemukan rumusan masalah sehingga ditentukan tujuan pelaksanaan Pengabdian Kepada Masyarakat dengan tema "Penguatan Satuan Paud Dengan Pendekatan Pembelajaran Berbasis STEAM dalam Pendidikan Abad 21". Secara umum tujuan pendampingan dan penguatan ini adalah dihasilkannya kegiatan pengabdian masyarakat berkualitas bidang Pembelajaran Berbasis STEAM di PAUD, serta terjalinnya kerjasama kelembagaan dalam rangka meningkatkan penguatan program studi yang marketable sesuai tuntutan stakeholder pendidikan dan non pendidikan. Secara khusus, tujuan pendampingan sesuai rumusan 
masalahnya adalah untuk mengoptimalkan lembaga PAUD dalam pelaksanaan pendekatan STEAM di PAUD sehingga terlaksana pembelajaran dengan pendekatan STEAM secara tepat pada proses pembelajaran di PAUD.

\section{Metode}

Workshop Penguatan Satuan Paud Dengan Pendekatan Pembelajaran Berbasis STEAM dalam Pendidikan Abad 21 dilaksanakan dengan melibatkan 24 orang guru Taman Kanak-kanak yang ada di Islam Terpadu (TKIT) Nurul Hidayah Sampang. Kegiatan dilaksanakan pada tanggal 25 November 2020 dengan materi konsep dan implementasi pembelajaran Pendidikan Anak Usia Dini berbasis STEAM, adapun deskripsi pelaksanaan kegiatan workshop sebagai berikut: Sesi Pertama Pada sesi pertama ini diisi dengan pengampaian materi yang berjudul "Pengembangan Kurikulum 2013 dan keterampilan Abad 21". Peserta diberikan pengetahuan tentang bagimana teknis mengembangkan konsep kurikulum 2013, agar semua peserta memiliki pemahaman yang sama mengenai pembelajaran berdasarkan kurikulum 2013. Berbekal pengetahuan tersebut dapat dijadikan sebagai landasan bagi guru / peserta untuk mengembangkan perencanaan pembelajaran (SOP, pedoman, prosem, RPPM, dan RPPH) berdasarkan kurikulum 2013 secara mandiri sesuai dengan kebutuhan anak usia dini.

Sesi Kedua Sesi kedua ini diisi dengan diskusi kelompok dan praktek secara langsung Pengembangan: Implementasi kurikulum 2013 dan implementasi metode STEAM. Semangat peserta pada kegiatan ini cukup baik, ada beberapa peserta workshop yang masih kesulitan untuk dari mana harus memulai mengidentifikasi situasi kemudian menyusun rencana pengembangan Implementasi kurikulum 2013 berasi STEAM. Tim Pengabdian Kepada Masyarakat program studi Pendidikan islam anak ausia dini fakutas tarbiyah institute agama islam negeri madura kemudian menyepakati untuk membantu membuat need assesmen pengembangan berdasarkan tema. . Keterbatasan yang dialami oleh peserta cukup wajar karena masih banyak guru PAUD yang belum paham betul penerapan kurikulum 2013, sehingga ketika akan melaksanakan kurikulum 2013 yang komponennya terdiri dari pengembangan tema, pemetaan $\mathrm{KI}$ dan KD dalam program semester, pengembangan RPPM, Penyusunan Tujuan Pembelajaran dan Indikator Pencapaian Pekembangan, pengembangan RPPH. Setelah melalui beberapa diskusi, mulai ditemukan beberapa cara efektif untuk mengembangkan tema, program semester dan RPPH. Dari kegiatan ini diharapkan kesulitan-kesulitan yang dihadapi peserta workshop ini dapat terselesaikan berdasarkan penjelasan dari fasilitator.

\section{Hasil dan Pembahasan}

Pelaksanaan kegiatan pengabdian kepada masyarakat dengan tema "Penguatan Satuan PAUD Dengan Pendekatan Pembelajaran Berbasis STEAM Dalam Pendidikan Abad 21" dijadwalkan dengan dua sesi, sesuai 
dengan rencana. Pelaksanaan di Taman Kanak-Kanak Islam Terpadu (TKIT) Nurul HidayahSampang pada hari Rabu, 25 Nopember 2020.

Jumlah peserta adalah 24 orang yang meliputi stakeholder yang berada di Taman Kanak-Kanak Islam Terpadu (TKIT) Nurul Hidayah Sampang, terdiri dari kepala sekolah dan guru dari Taman Kanak-Kanak Islam Terpadu (TKIT) Nurul Hidayah Sampang, serta 4 orang dosen PIAUD IAIN Madura.

Kegiatan workshop di Taman Kanak-Kanak Islam Terpadu (TKIT) Nurul Hidayah Sampang dilaksanakan di ruang pertemuanTaman Kanak-Kanak Islam Terpadu (TKIT) Nurul Hidayah Sampang dengan melalui tahapan sebagai berikut:

a. KegiatanPersiapan, meliputi:

1) Kegiatan survey tempat pengabdian kepada masyarakat Taman KanakKanak Islam Terpadu (TKIT) Nurul Hidayah Sampang.

2) Permohonan izin pengabdian kepada Kepala Taman Kanak-Kanak Islam Terpadu (TKIT) Nurul HidayahSampang

3) Pengurusan administrasi (surat-menyurat).

4) Persiapan alat dan bahan serta akomodasi.

5) Persiapan tempat untuk workshop.

b. Kegiatan Workshop

Secara sistematis, rangkaian kegiatan sesuai dengan waktu seperti tercantum dalam table 1.1. berikut ini.

Tabel 1. Matrik kegiatan "Penguatan Satuan PAUD Dengan Pendekatan Pembelajaran Berbasis STEAM Dalam Pendidikan Abad 21"

\begin{tabular}{|c|c|c|c|c|}
\hline Hari/Tanggal & Waktu & $\begin{array}{c}\begin{array}{c}\text { Kegiatan / } \\
\text { Materi }\end{array} \\
\end{array}$ & Narasumber & $\begin{array}{c}\text { Penaggung } \\
\text { Jawab }\end{array}$ \\
\hline $\begin{array}{c}\text { Selasa, } 24 \\
\text { Nopember } \\
2020 \\
\end{array}$ & $\begin{array}{c}08.00- \\
10.00\end{array}$ & Kunjungan awal & - & TIM PKM \\
\hline \multirow[t]{2}{*}{$\begin{array}{c}\text { Rabu, } \\
25 \text { Nopember } \\
2020\end{array}$} & $\begin{array}{l}08.00- \\
09.00\end{array}$ & $\begin{array}{l}\text { Materi : } \\
\text { Pengembangan } \\
\text { Kurikulum } 2013 \\
\text { dan keterampilan } \\
\text { Abad } 21\end{array}$ & $\begin{array}{l}\text { Jamiludin } \\
\text { Usman, } \\
\text { M.Pd.I }\end{array}$ & $\begin{array}{l}\text { Moderator: } \\
\text { Nina Khayatul } \\
\text { Virdyna, M.Pd }\end{array}$ \\
\hline & $\begin{array}{c}09.00- \\
11.00\end{array}$ & $\begin{array}{l}\text { Diskusi } \\
\text { Pengembangan: } \\
\text { Implementasi } \\
\text { kurikulum } 2013 \\
\text { dan implementasi } \\
\text { metode STEAM } \\
\text { dalam } \\
\text { pembelajaran } \\
\text { AUD }\end{array}$ & $\begin{array}{l}\text { Luthfatun } \\
\text { Nisa', M.Pd }\end{array}$ & $\begin{array}{l}\text { Moderator: } \\
\text { Danang } \\
\text { Prastyo, M.Pd }\end{array}$ \\
\hline
\end{tabular}




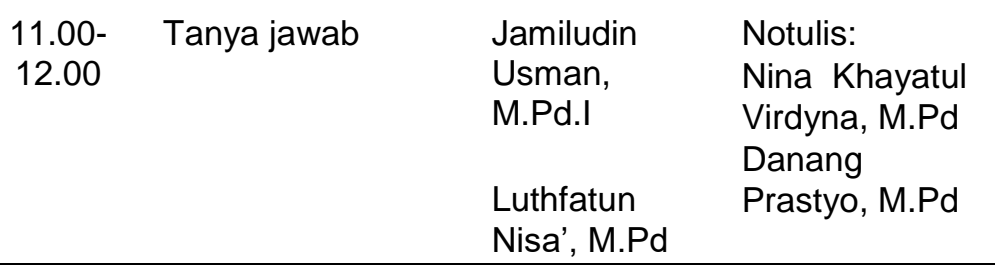

\section{c. Penutupan}

1) Doa

2) Pembuatan laporan

Kegiatan ini dilaksanakan selama satuhari dengan alokasi waktu 4 jam. Kegiatan dibagi menjadi dua sesi berdasarkan materi yang telah ditentukan. Pada sesi pertama kegiatan difokuskan pada pembahasan teoritis terkait kurikulum dan keterampilan abad 21, sedangkan pada sesi kedua difokuskan pada implementasi kurikulum yang diintegrasikan dengan keterampilan abad 21, serta implementasi metode STEAM dalam pembelajaran AUD.

Pada sesi pertama dilaksanakan pada pukul 08.00-09.00 WIB, materi disampaikan oleh Bapak Jamiludin Usman, M.Pd.I dan di moderatori oleh Ibu Nina Khayatul Virdyna, M.Pd. Pada sesi ini kegiatan dilakukan dengan metode ceramah dengan menyampaikan materi berikut:

a) Pengembangan kurikulum 2013

b) Keterampilan abad 21

c) Implementasi pembelajaran abad 21

Materi-materi yang disampaikan merupakan materi yang perlu disampaikan dan dibutuhkan oleh pendidik saat ini. Materi ini dianggap penting dikarenakan perlunya guru untuk dapat menyiapkan pembelajaran yang disesuaikan dengan tuntutan era saat ini dan juga melihat situasi dan kondisi saat ini yang telah banyak mengalami perubahan sehingga menuntut pendidik untuk cepat beradaptasi dalam menyesuaikan metode dan juga strategi pembelajaran.

Sesi kedua mulai dilaksanakan pada pukul 09-10.00 WIB, dan materi disampaikan oleh Ibu Luthfatun Nisa', M.Pd dan dimoderatori oleh Bapak Danang Prastyo, M.Pd. Pada sesi ini pemateri menyampaikan terkait penerapan dan pegintegrasian teori dan praktik dalam pembelajaran AUD. Materi yang disampaikan meliputi:

a) Implementasi pembelajaran abad 21

b) Pengintegrasian kurikulum 2013 dan keterampilan abad 21

c) Implementasi metode STEAM dalam pembelajaran AUD

Adapun hasil yang didapatkan dari program pengabdian kepada masyarakat ini sebagai berikut:

a) Dengan adanya program pengabdian masyarakat yang berupa workshop penguatan metode pembelajaran berbasis STEAM di Taman KanakKanak Islam Terpadu (TKIT) Nurul Hidayah Sampang ini dapat 
meningkatkan pengetahuan kepala sekolah dan guru dalam Penguatan Satuan PAUD Dengan Pendekatan Pembelajaran Berbasis STEAM Dalam Pendidikan Abad 21.

b) Dengan adanya program ini, kepala sekolah, dan guru diharapkan mengaplikasikan pengetahuan tentang Pendekatan Pembelajaran Berbasis STEAM pada lembaga pendidikan

c) Lebih jauh, diharapkan kegiatan-kegiatan serupadapat berdampak pada peningkatan kualitas pendidikan di Sampang, khususnya di kecamatan Sampang.

d) Mahasiswa yang terlibat menjadi tahu praktik tentang Penguatan Satuan PAUD Dengan Pendekatan Pembelajaran Berbasis STEAM Dalam Pendidikan Abad 21.

Kegiatan workshop tentang "Penguatan Satuan PAUD Dengan Pendekatan Pembelajaran Berbasis STEAM Dalam Pendidikan Abad 21" terlaksana dengan baik bahkan para peserta terlihat antusias dan mengharapkan kegiatan tersebut diadakan kembali pada masa yang akan datang. Tidak hanya peserta, para pengurus yayasan juga mengharapkan akan adanya kegiatan berkelanjutan sehingga semakin dapat meningkatkan kompetensi guru dan kepala sekolah.

Kegiatan Pengabdian Kepada Masyarakat dengan tema" Penguatan Satuan PAUD Dengan Pendekatan Pembelajaran Berbasis STEAM Dalam Pendidikan Abad 21" dapat dilaksanakan dengan baik disebabkan adanya beberapa faktor pendukung, diantaranya:

1. Adanya dukungan dari kepala sekolahTaman Kanak-Kanak Islam Terpadu (TKIT) Nurul Hidayah Sampang dalam penyelenggaraan kegiatan Pengabdian Kepada Masyarakat.

2. Fasilitas dan kemudahan yang diberikan oleh Kepala Sekolah

3. Para guru dan tenaga kependidikan di Taman Kanak-Kanak Islam Terpadu (TKIT) Nurul Hidayah Sampang sangat antusias dalam mengikuti kegiatan tersebut sampai selesai dibuktikan dengan daftar kehadiran mereka mencapai $100 \%$ sampai kegiatan selesai.

4. Sarana dan prasarana yang disediakan oleh Taman Kanak-Kanak Islam Terpadu (TKIT) Nurul Hidayah Sampang memungkinkan para peserta untuk mengikuti workshop.

5. Mudahnya administrator sekolah dalam memberikan data dan segala kebutuhan administrasi kegiatan.

\section{Kesimpulan}

Berdasarkan hasil pelaksanaan kegiatan Pengabdian Kepada Masyarkat (PKM) dengan tema "Penguatan Satuan PAUD Dengan Pendekatan Pembelajaran Berbasis STEAM Dalam Pendidikan Abad 21" bahwa kegiatan tersebut dapat dilaksanakan dengan baik sesuai dengan prosedur karena dukungan dan partisipasi dari kepala sekolah dan guru Taman Kanak-Kanak Islam Terpadu Nurul Hidayah Sampang yang benar-benar menginginkan kemajuan pada lembaga PAUD. 
Pelaksana program pengabdian ini menemukan bahwa Penguatan Satuan PAUD Dengan Pendekatan Pembelajaran Berbasis STEAM Dalam Pendidikan Abad 21 ini sangat penting dilakukan dengan mengkolaborasikan metode yang telah banyak dikuasai oleh guru-guru dan memanfaatkan media yang ada dilingkungan, sehingga memaksimalkan proses pembelajaran. Pembinaan dan pembimbingan yang telah dilakukan secara umum telah memberikan Penguatan Satuan PAUD Dengan Pendekatan Pembelajaran Berbasis STEAM Dalam menyongsong Pendidikan di Abad 21.

Berdasarkan temuan pada kegiatan Pengabdian Kepada Masyarkat (PKM) dengan tema "Penguatan Satuan PAUD Dengan Pendekatan Pembelajaran Berbasis STEAM Dalam Pendidikan Abad 21" direkomendasikan bahwa perlu adanya pemahaman teori pendekatan pembelajaran STEAM dan implementasi secara nyata, kemudian perlu kerjasama yang harmonis antar lembaga pendidikan di Taman Kanak-Kanak Islam Terpadu (TKIT) Nurul Hidayah Sampang dalam rangka meningkatkan kualitas dan mutu pendidikan, dan Bagi Taman Kanak-Kanak Islam Terpadu (TKIT) Nurul Hidayah Sampang dengan kepala sekolah dan gurunya untuk terus melakukan inovasi dan Penguatan Satuan PAUD Dengan Pendekatan Pembelajaran Berbasis STEAM Dalam Pendidikan Abad 21 agar hasil pebelajaran dapat berjalan secara optimal.

\section{Daftar Pustaka}

Anjarsari, Novia. (2019). Kesiapan Guru terhadap Penerapan (Science, Technology, Engineering, Mathematics) (Survei pada Guru TK Se Kecamatan Gunung Pati Kota Semarang). UNNES.

Artobatama, I. (2018). Pembelajaran STEM Berbasis Outbound Permainan Tradisional. Indonesian Journal of Primary Education, 2(2), 40-47. doi: 10.17509/ijpe.v2i2.15099

Jatnika, Y. (2019). Begini Cara Ajari Anak STEAM untuk Menghadapi Masa Depan | Sahabat Keluarga. Retrieved 8 January 2021, from Sahabat Keluarga, Kementerian Pendidikan dan Kebudayaan website: https://sahabatkeluarga.kemdikbud.go.id/laman/index.php?r=tpost/xvie w\&id $=249900766$

Nisa' Luthfatun. (2017). Sistem Pendidikan Pesantren sebagai Sarana Meningkatkan Keterampilan Hidup Sejak Dini sebagai Bekal di Masa Depan. Prosiding KMP Education Research Conference.

Pacific Policy Research Center. (2010). 21st Century Skills for Students and Teachers. Hanolulu: Kamehameha Schools: Research and Evaluation Division.

Partnership for 21st Century Skills. 2010 21st Century Knowledge and Skills in Educator Preparation. America Association of Colleges of Teacher Education and The Partnership for $21^{\text {st }}$ Century Skills (AACTE). 
Usman, J. (2018). Kaidah-Kaidah Dasar Pendidikan Anak (Studi Komparasi Pemikiran Abdullah Nasih Ulwan dengan Maria Montessori). TADRIS: Jurnal Pendidikan Islam, $13 \quad$ (1), 149 - 167. doi:http://dx.doi.org/10.19105/tjpi.v13i1.2052 